\title{
NEW PERSPECTIVES AFTER THE TRANSITION OF EPIET TO ECDC - THE FUTURE OF THE PROGRAMME
}

\author{
V Bremer (viviane.bremer@ecdc.europa.eu) ${ }^{1}$, A Bosman $^{1}$, D Coulombier ${ }^{1}$ \\ 1. Preparedness and Response Unit, European Centre for Disease Prevention and Control (ECDC), Stockholm, Sweden
}

This article was published on 29 0ctober 2009.

Citation style for this article: Bremer V, Bosman A, Coulombier D. New perspectives after the transition of EPIET to ECDC - the future of the programme. Euro Surveill. 2009;14(43):pij=19374. Available online: http://www.eurosurveillance.org/ViewArticle.aspx?ArticleId=19374

\begin{abstract}
Strengthening capacity in intervention epidemiology is key to the overall goal of responding to the challenge to detect and counter threats posed by outbreaks of infectious diseases in the European Union (EU). Since its founding in 1995, the European Programme for Intervention Epidemiology Training (EPIET) has become a core resource in training in intervention epidemiology in the EU. EPIET was integrated into the European Centre for Disease Prevention and Control (ECDC) on 1 November 2007 and this has resulted in an increased sustainability of the programme, allowing for longterm planning. Also, a new training programme, the European public health microbiology training (EUPHEM), was set up in 2008 to increase the response capacity for microbiology. Collaboration with EU Member States and other training programmes has been further intensified. Merging EPIET and other training activities in the ECDC training section has created the opportunity to develop an integrated multilevel approach to training in applied field epidemiology. An integrated approach to training activities on EU level, and increasing the number of EPIET and EPIET-associated fellows are essential to respond to the training needs of EU Member States, particularly new Member States. An external evaluation of EPIET in 2009 will provide guidance for a future strategy for the programme. This article examines the achievements of the EPIET programme after its transition to ECDC and provides an outlook on its future.
\end{abstract}

\section{Introduction}

The European Programme for Intervention Epidemiology Training (EPIET) was created in 1995 [1, 2]. The aims of EPIET are to develop a European network of intervention epidemiologists using commonly agreed methods, to build a response capacity inside and beyond the European Union (EU) and to strengthen communicable disease surveillance and control in EU Member States and at Community level. The programme is aimed at EU health professionals with previous experience in public health and a strong interest in epidemiology. The purpose of the programme is for EPIET fellows to gain practical experience in intervention epidemiology [1].

The programme lasts two years and is competency-based [3] with a 'learning by doing' approach. It starts with a three-week introductory course in infectious disease epidemiology. Following the introductory course, fellows spend 23 months at a training site at a national or regional centre for surveillance and control of communicable diseases in an EU Member State or Norway [4, 5], different from the country of origin of the fellow. Ten percent of the time of the programme is used for formal training courses and the remainder for supervised activities at a training site, where fellows are considered as a part of the public health workforce and are required to perform outbreak investigations as well as to carry out projects in the area of surveillance and do research on relevant public health issues. In addition, they are expected to present the results of their work to the scientific community during the European Scientific Conference on Applied Infectious Disease Epidemiology (ESCAIDE) and publish in peer-reviewed journals.

EPIET was integrated into the European Centre for Disease Prevention and Control (ECDC) on 1 November 2007 [6]. Prior to its integration, the European Commission and EU Member States were funding the programme and the salaries of the fellows on a project basis. The Swedish Institute for Infectious Disease Control administrated the budget and hosted the EPIET programme office responsible for all logistical and administrative issues between 2002 and 2007. Representatives of the training sites provided guidance on the programme strategy through the annual meeting of the EPIET Steering Committee. This article examines the changes within the EPIET programme after the transition to ECDC and provides an outlook on the future of the programme.

\section{Evolution of EPIET after transition to ECDC \\ Administration}

Since November 2007, EPIET is part of the section for Epidemiological Training of ECDC's Preparedness and Response Unit (PRU) and has a secured budget since its integration into ECDC. The EPIET programme office at ECDC continues to handle logistical and administrative issues of the fellows. The EPIET chief coordinator is also based at ECDC in Stockholm in the Section for Epidemiological Training. A framework partnership agreement between ECDC and four European national institutes for public health (Robert Koch-Institute, Institut de Veille Sanitaire, Health Protection Agency, Instituto Carlos III) has allowed the placement of the other EPIET scientific coordinators in Germany, France, the UK and Spain, also after the transition to ECDC. The fellows' contracts, salaries, removals and travel arrangements are handled by ECDC's Administrative Service Unit.

One year before the transition, starting in October 2006, ECDC took over the funding of EPIET fellows previously paid by the EU Commission. ECDC recruited fellows of the cohorts 12 to 14 and placed them in the training sites. Salaries offered by Member States were used to fund additional fellows. Since 2009, all salaries were transformed into individual grants. The former EPIET steering committee was replaced by the EPIET Training Site Forum to allow continued input from the Member States after the 
transition to ECDC. All national training sites, a representative for the fellows currently in training and the EPIET alumni association are represented in the EPIET Training Site Forum. The Forum provides feedback on the functioning of the curriculum and current programme, identifies training needs for trainers, and participates in the recruitment of fellows and facilitators.

\section{Growth of EPIET}

The number of salaries provided for trainees increased from nine in 2002 to 19 in 2009. Before the transition, the number of salaries funded by Member States needed to equal at least those funded from the EU budget. This condition has been removed and in 2008 most salaries (84\%) were funded by the ECDC. In addition to the increase of fellows funded by ECDC and Member States, a rising number of Member States started training fellows at national EPIET training sites. These fellows participate at EPIET modules and EPIET scientific coordinators review their progress, using the same appraisal criteria as for EPIET fellows. After successful completion of the training, these fellows also receive the EPIET diploma. This type of training is referred to as an "EPIET-associated programme". In 2008, four fellows recruited by Germany for the Postgraduate training for Applied Epidemiology (PAE) and one fellow recruited by Finland, Slovenia and Norway, respectively, were included into EPIET [6]. Thus, a total of 26 fellows have been included in the 14th EPIET cohort which started in September 2008 (Figure).

Compared to 2002 (cohort 7/8), the number of fellows currently in training (cohort 13/14) has increased from 28 to 47 , corresponding to an increase of $68 \%$.

\section{F I G U R E}

Number of EPIET, German Postgraduate training for Applied Epidemiology (PAE), EPIET-associated and EUPHEM fellows, 1995-2009 $(n=141)$

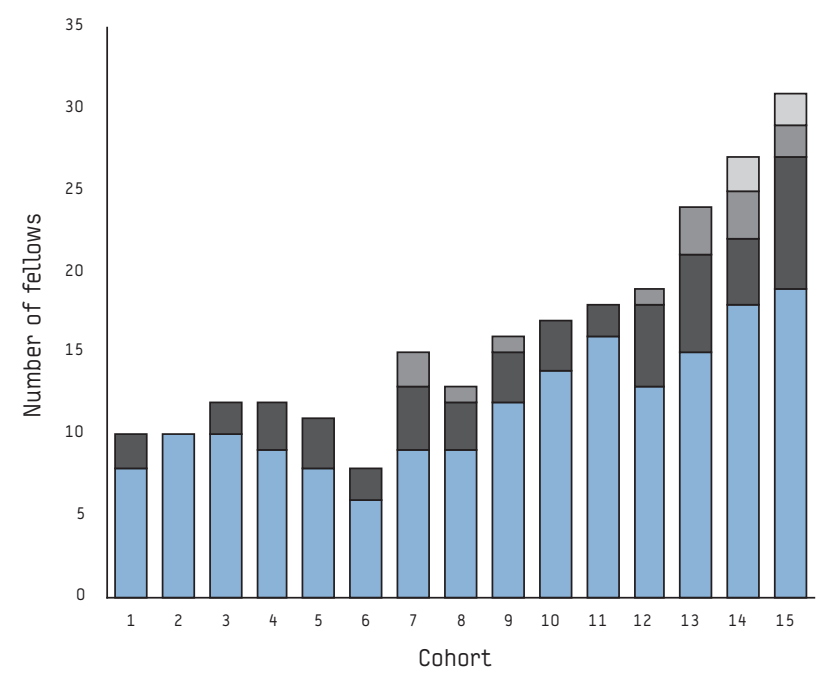

$\square$ European public health microbiology training-EUPHEM $(n=2)$

EPIET-associated programme $(n=13)$

German Postgraduate training for Applied Epidemiology (PAE) $(n=50)$

EPIET $(n=176)$
Following the growth of the number of fellows, the number of EPIET scientific coordinators has increased from four to six, which corresponds to an increase of 2.8 to currently 4.4 full time equivalents.

\section{Public Health Microbiology training programme}

A laboratory component has been introduced by some field epidemiology training programmes in recent years [7]. In 2008 two EPIET salaries were used for the first time to recruit two fellows for the newly created European public health microbiology training (EUPHEM). The aim of this two-year pilot training is to develop a European network of public health microbiologists, a response capacity for microbiology inside and beyond the EU and to strengthen communicable disease surveillance and control through an integrated laboratory-field epidemiology network for outbreak detection, investigation and response EUPHEM fellows are placed in national public health laboratories and carry out outbreak investigations, surveillance and research activities in close collaboration with epidemiologists. Another aim of the placement is to develop skills in laboratory techniques and understand the specific methods, challenges and requirements for public health laboratories. EUPHEM fellows follow some of the modules of the EPIET programmes and are currently monitored by EPIET scientific coordinators.

\section{International collaboration}

Since the start of EPIET, the programme has relied strongly on the contribution from Member States. Fellows are currently hosted and trained in 21 training sites in the EU Member States and Norway. Estimating an average of four hours of supervision per week, these training sites contributed a total of 8,000 hours in 2008. EPIET continues to recruit facilitators for its modules from the pool of senior epidemiologists and EPIET alumni working in national or regional public health institutes. In 2008, they contributed a total of 37 weeks of facilitation to EPIET modules and a large proportion of these was provided by the Member States hosting EPIET-associated fellows.

EPIET aims to intensify its collaboration with the Training Programs in Epidemiology and Public Health Interventions Network (TEPHINET), which is a professional alliance of field epidemiology training programmes (FETPs), located in thirty-two countries around the world linking all existing field epidemiology training programmes [8]. Among other activities, EPIET/ECDC exchanged trainers and organised joint events with other independent FETPs, for example with the French and Spanish programmes, PROFET and PEAC as well as the Canadian Field Epidemiology Program.

\section{Conclusions and recommendations}

\section{Integration of EPIET into ECDC}

The transition of EPIET from an EU funded project to ECDC has resulted in increased sustainability of the programme. This opens the possibility for long-term planning of training in field epidemiology in the EU. In addition, merging EPIET and other training activities in the ECDC training section has created the opportunity to develop an integrated multilevel approach to training in applied epidemiology. An integrated approach to all training activities is essential to address training needs of EU Member States at national and regional level and should be pursued further.

\section{Future growth of EPIET}

Training more EPIET fellows is necessary in order to respond to the need for public health epidemiologists in Member States. 
Strengthening capacity in intervention epidemiology is key to the overall goal of responding to the challenge to detect and counter threats posed by outbreaks of infectious diseases in the EU. Even though the number of fellows increased substantially over the past six years, it is still insufficient to fulfil the needs in all 27 Member States. Large Member States need to recruit a large number of fully trained epidemiologists at local, regional or national level. The majority of the twelve new Member States do not yet have any EPIET alumni who have returned to work in their country of origin. Finally, two thirds of EPIET alumni currently work in Member States at either national or regional level, while the remainder started working at international level, in the private sector or outside Europe [10].

Therefore the number of EPIET fellows needs to be increased further to respond to the needs of Member States. Especially training of fellows from new Member States is of outmost importance. In addition, ECDC and Member States need to consider developing strategies to facilitate the return of EPIET alumni to their countries of origin. The creation of more FETP or EPIETassociated programmes might contribute to build local capacities, as fellows trained in their own country are more likely to remain there after graduation and contribute to intervention epidemiology [10].

EUPHEM will contribute to create a network of professionals who will be able to collaborate with epidemiologists in the field of surveillance, outbreak investigation and applied research and this increased cross-sectoral cooperation will strengthen the capacity of outbreak investigation. Similarly to EPIET, EUPHEM requires a network of trainers available for supervision and coordination of the programme.

\section{International collaboration}

EPIET will continue to rely on the existing excellent collaboration with training sites in the Member States which are identified through a structured appraisal process by the EPIET scientific coordinators. Up to now, only few training sites are located in new Member States. With a growing number of fellows, there is a strong need for new training sites with experienced training site supervisors, teachers and facilitators. The number of experienced trainers available to teach highly specialised topics in intervention epidemiology is limited. Therefore, the training of future trainers is of high importance to ensure the quality of the EPIET programme. ECDC has started to address this issue by coordinating four workshops organised by the EPIET alumni association, TEPHINET, the Canadian Field Epidemiology Training Programme and the Robert Koch Institute. These workshops were specifically aimed at trainers and arranged around ESCAIDE. These efforts need to be continued to assure that a sufficient number of experienced trainers will be available.

Most of the EPIET scientific coordinators work at Member States' level and this has helped to maintain strong links with Member States. EPIET has reinforced the links to national institutes which host EPIET-associated programmes by increasing the number of facilitators originating from them. This collaboration, as well as maintaining strong links between EPIET and independent FETPs such as the French Programme de formation à l'épidémiologie de terrain (PROFET) and Spanish Programa de Epidemiología Aplicada de Campo (PEAC), is extremely useful to facilitate the sharing of resources and the development of joint training materials.
TEPHINET has the potential to become the platform for these exchanges. EPIET should therefore take a more active role in TEPHINET, especially on the European level.

In addition to the collaboration with the Member States, ECDC's technical units for Preparedness and Response, Surveillance, Scientific Advise and Health Communication are increasingly offering activities corresponding to the EPIET objectives [11, 12, 13]. Therefore, EPIET will promote the involvement of its fellows in projects carried out by ECDC.

\section{Challenges}

After the integration into ECDC, the EPIET has developed into the most important source of training in intervention epidemiology in the EU. In the past it has played central role in building a public health capacity in surveillance, outbreak investigation and applied research in the EU and it will continue to do so in the future. Whether linking the successful completion of EPIET to an academic title would help to increase the programme's visibility and reputation has been discussed repeatedly. For example, the PEAC is tied to a master degree [14]. Similarly, the German PAE cohort starting in 2009 will be awarded a Master of Science in Applied Epidemiology at the end of their training. EPIET modules will count as an integral part of their theoretical training [15].

An external evaluation of the programme has been commissioned that will take place in 2009. It will provide strategic advice and guidance for the future development of EPIET and address the future role of EPIET-associated programmes.

\section{Acknowledgements}

We thank the EPIET scientific coordinators Alicia Barrasa, Marion Muehlen, Brigitte Helynck, Doris Radun, Marie-Anne Botrel and the coordinator of the German PAE programme Katharina Alpers for their comments of the manuscript.

\section{References}

1. Moren A, Drucker J, Rowland M., Van Loock F. [European Program for Intervention Epidemiology Training (EPIET): a training epidemiologic intervention in Europe]. Rev Epidemiol Sante Publique. 1998;46(6): 533-40. French.

2. van Loock F, Rowland M, Grein T, Moren A. Intervention epidemiology training: a European perspective. Euro Surveill. 2001;6(3):pij=218. Available from: http:// www.eurosurveillance.org/ViewArticle.aspx?ArticleId=218

3. European Centre for Disease Prevention and Control (ECDC). Core competencies for public health epidemiologists working in the area of communicable disease surveillance and response, in the European Union. ECDC. Stockholm, 2008. Available from: www.ecdc.europa.eu/en/publications/Publications/0801 TED_Core_Competencies_for_Public_Health_Epidemiologists.pdf

4. Bremer V. [Infectious disease epidemiology education and training Programs. FETP and EPIET]. German. Bundesgesundheitsblatt Gesundheitsforschung Gesundheitsschutz. 2005;48(9):1049-54

5. Ammon A, Hamouda 0, Breuer T, Petersen LR. The Field Epidemiology Training Program (FETP) in Germany. Euro Surveill. 2001;6(3):pij=219. Available from: http://www.eurosurveillance.org/ViewArticle.aspx?ArticleId=219

6. Bremer V, Alpers K, Krause G. [Intervention epidemiology training programs in Germany and Europe. An investment in our future]. German. Bundesgesundheitsblatt Gesundheitsforschung Gesundheitsschutz. 2009; 52(2):203-7.

7. Kariuki Njenga M, Traicoff D, Tetteh C, Likimani S, Oundo J, Breiman R, et al. Laboratory epidemiologist: skilled partner in field epidemiology and disease surveillance in Kenya. J Public Health Policy. 2008;29(2):149-64

8. Cardenas VM, Roces MC, Wattanasri S, Martinez-Navarro F, Tshimanga M, AlHamdan N, et al. Improving global public health leadership through training in epidemiology and public health: the experience of TEPHINET. Training Programs in Epidemiology and Public Health Interventions Network. Am J Public Health. 2002;92(2):196-7. 
9. ECDC. Training strategy for intervention epidemiology in the European Union. 3rd ECDC Consultation with the Member States. Meeting Report (in press).

10. Bosman A, Schimmer B, Coulombier D. Contribution of EPIET to public health workforce in the EU, 1995-2008. Euro Surveill. 2009;14(43):pii=19381. Available from: http://www.eurosurveillance.org/ViewArticle.aspx?ArticleId=19381

11. Rantala M, van de Laar MJ. Surveillance and epidemiology of hepatitis B and $C$ in Europe - a review. Euro Surveill. 2008;13(21). pii: 18880. Available from: http://www.eurosurveillance.org/ViewArticle. aspx?ArticleId $=18880$

12. Kreidl P, Buxbaum P, Santos-O'Connor F, Payne L, Strauss R, Hrabcik H, et al. European Football Championship--ECDC epidemic intelligence support." Euro Surveill. 2008;13(32). pii: 18946. Available from: http://www.eurosurveillance. org/ViewArticle. aspx?ArticleId $=18946$

13. Grandesso F, Seyler T, Depoortere E. Assessing the risk of importing dengue and chikungunya viruses to the EU. Abstract Book. Berlin, 19-21 November 2008, p. 43. Available from: www.2008.escaide.eu/site/download.cfm?SAVE=1603\&LG=1

14. Martinez Navarro JF, Herrera D, Sanchez Barco C. Applied field epidemiology programme in Spain. Euro Surveill. 2001;6(3): 46-7.

15. Krause G, Aavitsland P, Alpers K, Barrasa A, Bremer V, Helynck B, et al. Differences and Commonalities of National Field Epidemiology Training Programmes in Europe. Euro Surveill. 2009;14(43):pii=19378. Available from: http://www.eurosurveillance.org/ViewArticle.aspx?ArticleId=19378 